\title{
Numerical and Experimental Test on an Innovative Device Based on Multiple Rotors in Line to Tap Clean Energy from Tidal and River Current
}

\author{
D.P. Coiro ${ }^{1}$, F. Scherillo ${ }^{2}$, G. Troise ${ }^{2}$, N. Bizzarrini ${ }^{1, *}$ and G.Calise ${ }^{1}$ \\ ${ }^{1}$ Department of Industrial Engineering- Aerospace Division, University of Naples "Federico II", Italy \\ ${ }^{2}$ Seapower Scarl Research Consortium, Via Claudio 21 - 80125 Napoli - Italy
}

\begin{abstract}
The main object of this paper is to present the design and the results of an experimental test campaign on an innovative device for the exploitation of marine and river currents. The basic idea is to lay together one or more series of horizontal axis turbines in rows, each one connected to a generator placed on board a ship or a float. The whole system is sustained by a series of buoys, in this way is possible to avoid expensive submarine installations. All the work has been carried out at the Department of Industrial Engineering of the University of Naples "Federico II" and the test campaign has been first performed in the naval towing tank belonging to the same Department and then in real conditions in Messina Strait between Sicily island and mainland. This location is the only one in Italy suitable as test site thanks to a highly regular tidal current reaching a maximum speed of $3 \mathrm{~m} / \mathrm{s}$. The turbine's blade was first carefully designed with particular care for the cavitation problems. Two different series of experimental tests on a reduced scale model in the naval tank aimed to optimize the general layout of the device and the tests performed in Messina Strait mainly aimed to confirm the feasibility of the system and to evaluate its response in real operating conditions. The tests have confirmed the good dynamic behavior of the whole system and its feasibility to be scaled up to real scale.
\end{abstract}

Keywords: Hydro turbines, Blade design, Floating platform, Towing tank tests, Real conditions tests.

\section{INTRODUCTION}

In this paper the design, realization and testing of an innovative device, developed in cooperation with research consortium Sea Power Scarl, for the exploitation of tidal and river current energy, will be described.

Although not yet widely used, tidal power has potential for future electricity generation. Tides are more predictable than wind energy and solar power. There are different types of systems to exploit the tidal energy; one of the most popular, because the lower cost and the lower ecological impact, is the tidal stream generator. Up to now the majority of tidal stream devices are based on horizontal and vertical axis hydro turbines. There are some working prototypes in the world like Kobold [1] and GEM [2] developed at the Department of Industrial Engineering of our university, the KHPS system [3, 4] developed by Verdant Power, SeaGen $[5,6]$ developed by Marine Current Turbines (MCT), Clean Current turbines [7] and the Lunar Tidal Turbine (LTT) [8] developed by Lunar Energy.

The Kobold system is a vertical axis and variable pitching blades hydro turbine; the GEM is an underwater vehicle linked to the seabed by means of a

*Address correspondence to this author at the Department of Industrial Engineering- Aerospace Division, University of Naples "Federico II", Italy; Tel: +39 081 7683329; E-mail: n.bizzarrini@seapowerscrl.com tether and supporting two horizontal-axis hydroturbines, which is characterized by its passive capacity of aligning itself along the current direction; the KHPS system (Kinetic Hydropower System) is an horizontal axis hydro turbine designed to self-rotate into the prevailing current; SeaGen consists of two axial flow, pitch controlled rotors fixed to a central support structure; Clean Current turbine is a shrouded hydro turbine with a central yawing bearing to provide the rotor with the ability to orient itself directly in-line with the current main direction; finally, the Lunar Tidal Turbine (LTT) is a bi-directional horizontal axis hydro turbine housed in a symmetrical Venturi duct which draws and accelerates the tidal flow through the turbine ensuring the optimum angle of approach as well as the increase of energy captured by the turbine without the need for blade pitch control.

However most of these installations, particularly for the horizontal turbines case, require massive submarine foundations. The prototype that will be described in this paper has the advantage to avoid this problem. The main idea of the device is to have several horizontal axis turbines set in row on the same transmission shaft and suitably spaced along the shaft.

The shaft goes out of the water and its end is connected to the electrical generator installed on a floating platform. In this way there is the further advantage to have all the delicate parts respect to the aggressive marine environment, out of the water. The 
weight of the shaft and of the turbines is balanced trough several buoys linked to bearings distributed along the shaft. For a general picture of the system, see Figure 1.

The main disadvantage of the system is that the turbines are aligned in rows so that the rear turbines are in the wake of the forward ones with a consequent loss in efficiency.

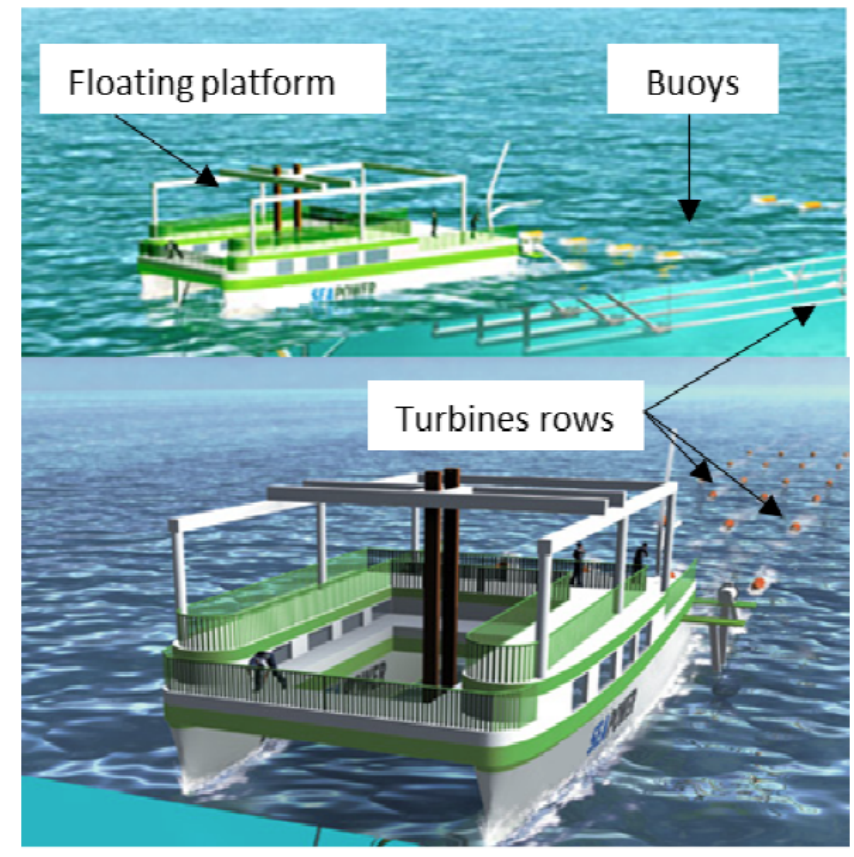

Figure 1: System pictorial view.

After an initial phase during which blade airfoils, chord and twist distribution have been designed, numerical estimations have been carried out on the performance behaviour of two turbines spaced at different distances. Then a first experimental test has been carried out in the towing tank of the Department of Industrial Engineering of our university in order to optimize the distances between the turbines without an excessive loss in efficiency of the whole system. In this first test campaign only one line made of 5 turbines has been investigated. Then a second test campaign has been set up with four different lines, each with 5 turbines, making a total of 20 turbines tested at same time. Different geometries and arrangements have been tested to optimize the final configurations. Finally a "real field" experiment was carried out employing the same hydro turbines used for naval towing tank campaign. The tests have been performed in the Strait of Messina in a location where a highly regular tidal current of maximum speed around $2.5 \mathrm{~m} / \mathrm{s}$ is present. The electrical parts, set at the end of transmission shaft, were placed on a boat that has been in turn moored on the seabed.

\section{BLADE DESIGN}

The blades were designed using airfoils with thickness decreasing from root to tip to accommodate both structural and aerodynamic needs. In order to have thicker airfoil at the root and thinner at the tip it has been chosen to use two different airfoils.

A thick airfoil (Figure 2) was designed for sections between $15 \%$ and $35 \%$ of the blade radius, while, for the rest of the blade, an 'ad hoc' modified airfoil (Figure 3) was used.

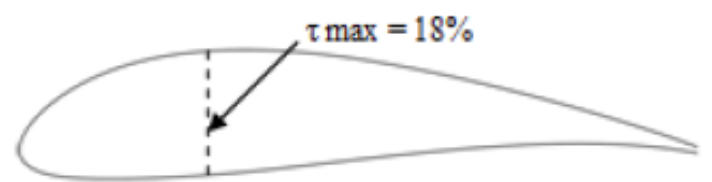

Figure 2: Root airfoil.

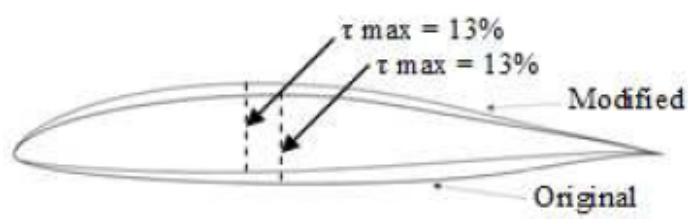

Figure 3: Tip modified airfoil GT1.

The tip airfoil was designed ad hoc in order to have high aerodynamic efficiency (defined as the lift $(L)$ to drag (D) ratio) at the design lift coefficient and Reynolds number. The airfoil shape was optimized using a gradient based method starting from a reference airfoil.

The code used for the optimization was developed at the Department of Industrial Engineering of our University [9].

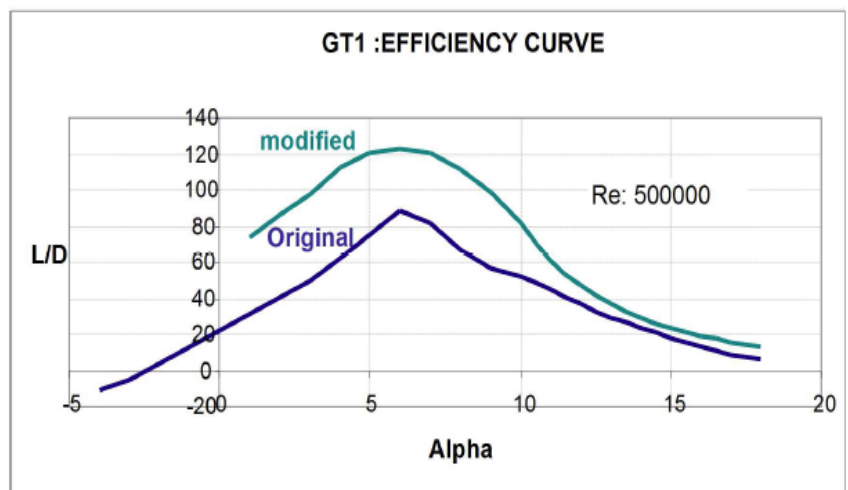

Figure 4: GT1 efficiency curve. 
Numerical estimations results reported in Figure 4 show that the modified airfoil exhibits a $50 \%$ efficiency increase with respect to the original one.

The design of the blade tip airfoil was performed in order to avoid cavitation. Cavitation occurs when the absolute value of the local pressure coefficient on the airfoil, $|c p|$, is greater then the cavitation number, $\sigma_{v}$. According to this, the blade tip airfoil was designed to obtain $|c p|<\sigma_{v}$ for the pressure distribution corresponding to $\mathrm{Cl}_{\max }$ where high negative pressure peak is reached.

The blades chord and twist distributions were optimized to maximize the power coefficient of the turbine at a given Tip Speed Ratio (TSR). The optimization has been performed using a numerical code based on the Glauert theory and developed at the Department of Industrial Engineering of our University.

Once the blade geometry has been fixed the rotor performances were evaluated at a wide range of TSR (Figure 5) using a numerical code based on the classical Blade Element Theory.

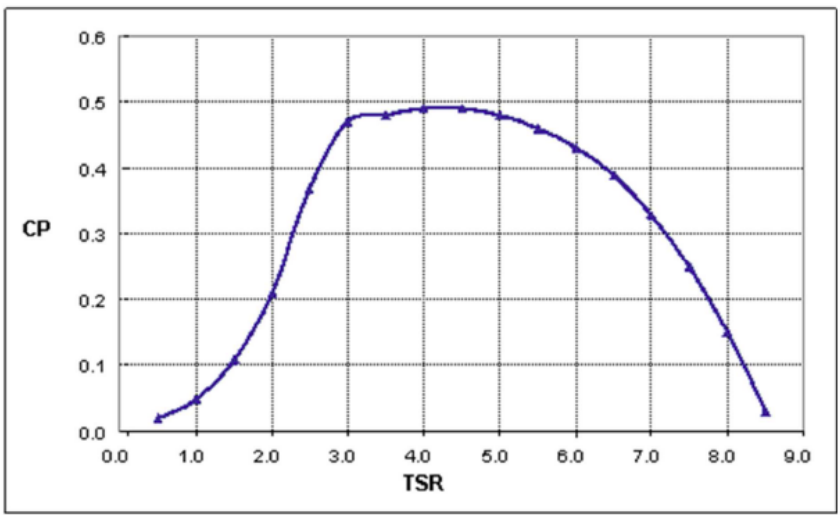

Figure 5: Power coefficient vs Tip speed ratio.

The numerical power coefficient curve shows a wide band of TSR (from 3 to 5) where it reaches a good efficiency: this was designed on purpose since the turbine has fixed pitch.

The designed rotor, built in fibreglass and shown in Figure 6 , has a diameter of $0.6 \mathrm{~m}$.

\section{TOWING TANK EXPERIMENTAL TESTS}

The experimental campaign was carried out, at the towing tank of the Department of Industrial Engineering of the University of Naples "Federico II" (length $120 \mathrm{~m}$, width $9 \mathrm{~m}$, depth $4 \mathrm{~m}$ ) testing two different configurations. A first configuration made of a single line of turbines (Figure 7) was tested in order to mainly investigate the minimal longitudinal distance between the turbines that minimizes the system efficiency loss.

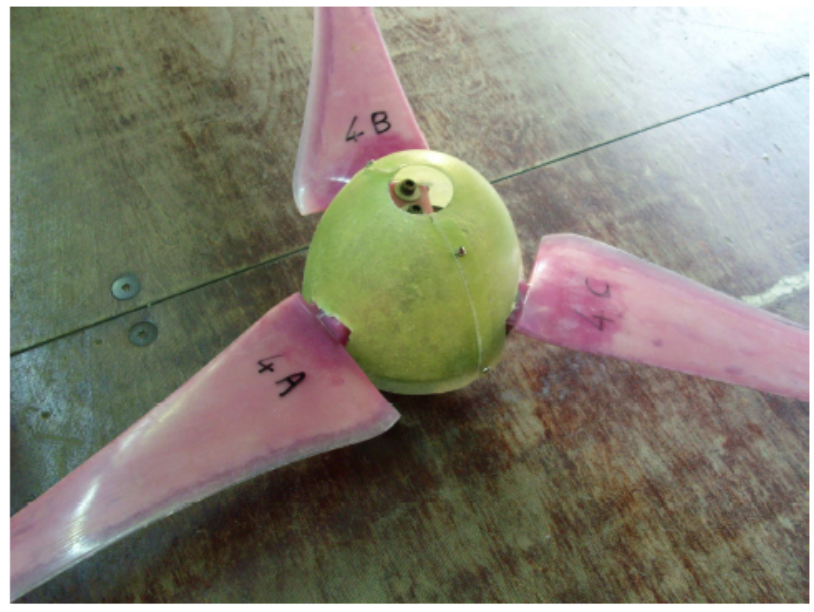

Figure 6: Turbine rotor.

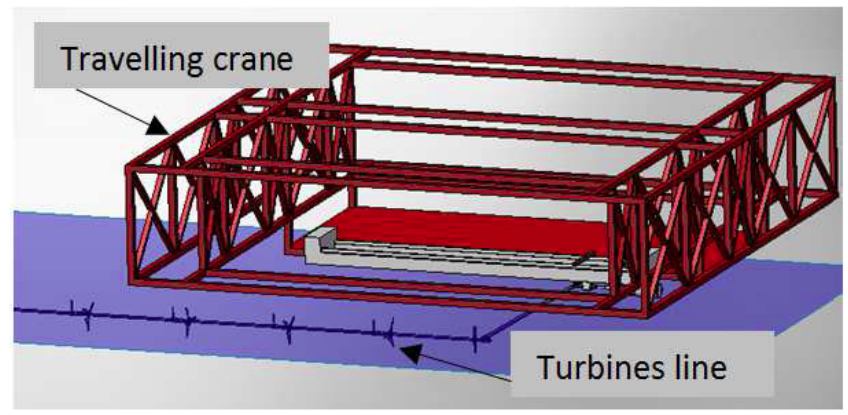

Figure 7: Single line towing tank setup.

Another test was carried out on a system of four lines of turbines, arranged in a box configuration, investigating the influence of the lateral distance of the turbines and the behaviour of such complex arrangement (Figure 8).

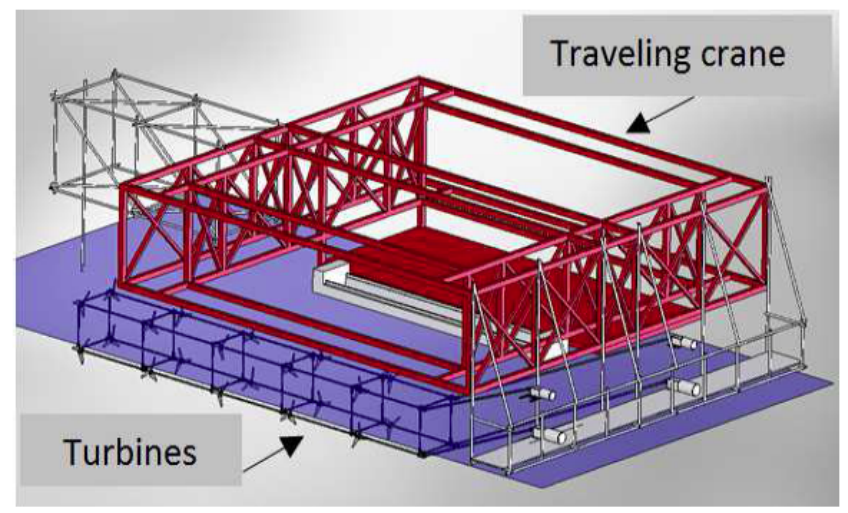

Figure 8: Four lines towing tank setup.

Each line was formed by five different pipes connected each other with cardanic joints. Each shaft 
section was equipped with a bearing linked in turn to the floating buoy capable of holding the pipe plus hydro turbine weight (Figure 9).

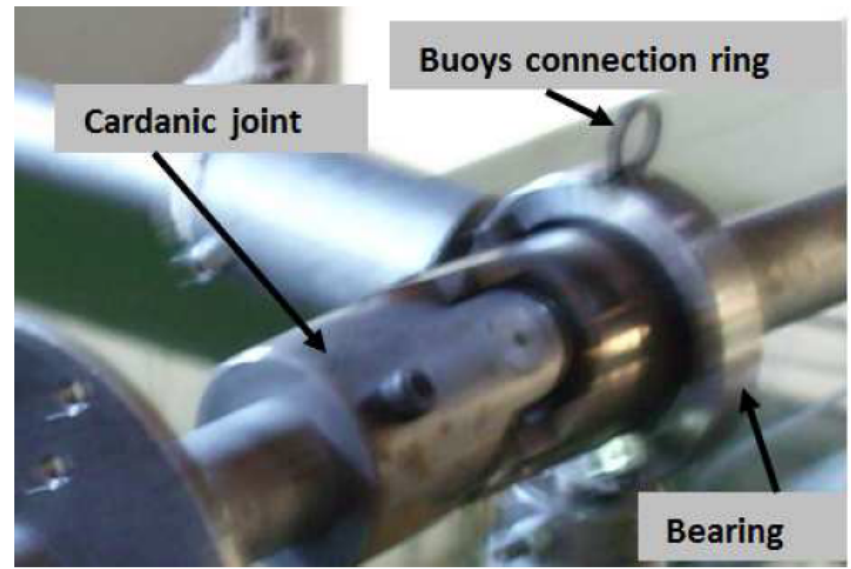

Figure 9: Shafts connection.

The towing tank tests were carried out using an electrical engine/brake for each line controlled by a closed loop feedback system which allowed of setting and holding a specific rotational speed (Figure 10). Since the electrical engine can work either as a brake or as a motor, it was possible to test the line for every desired combination of angular speed and current velocity. A torque-meter was placed between the electrical engine and the line in order to measure the torque and RPM.

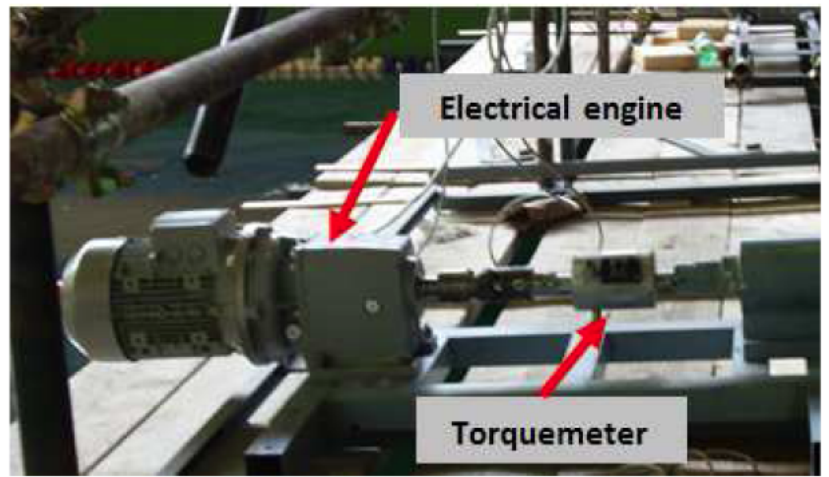

Figure 10: Electrical engine/brake.

On each line it was possible to install a maximum of 5 turbines.

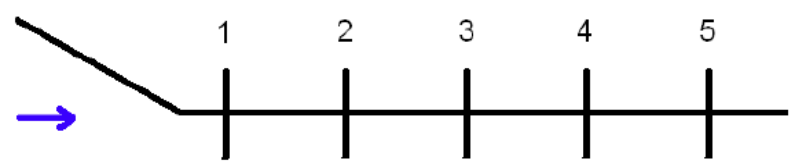

Figure 11: Turbine positions along the line.

The first experiments, performed on a single line, were carried out testing a different number of turbines set at different longitudinal positions (Figure 11). The distance between two consecutive positions was about 3.33 turbine diameter.

The different tests performed are reported in Table 1 (please refer to Figure $\mathbf{1 1}$ for the longitudinal positions).

Table 1: Different Tests Performed

\begin{tabular}{|c|c|}
\hline Number of turbines Installed & Tested Positions \\
\hline \multirow{2}{*}{1} & 1 \\
\cline { 2 - 2 } & 5 \\
\cline { 2 - 2 } 2 & $1-2$ \\
\cline { 2 - 2 } 2 & $1-3$ \\
\cline { 2 - 2 } & $1-4$ \\
\hline \multirow{2}{*}{3} & $1-5$ \\
\hline \multirow{2}{*}{4} & $1-2-3$ \\
\hline \multirow{2}{*}{5} & $1-3-5$ \\
\hline
\end{tabular}

The water current velocities tested were principally: $2 \mathrm{~m} / \mathrm{s}, 2.5 \mathrm{~m} / \mathrm{s}$.

Figure 12 shows the comparison of power coefficient for a single turbine set first in position 1 and then in position 5 .

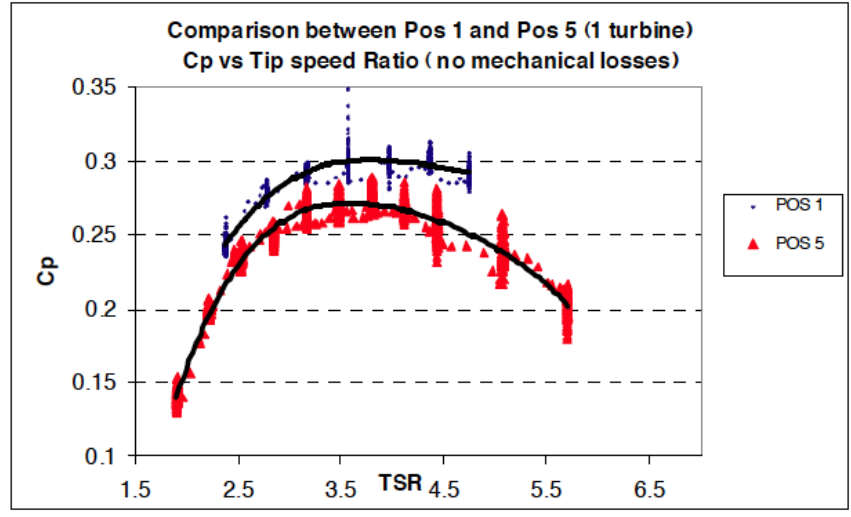

Figure 12: Comparison between pos. 1 and pos. 5 .

As it can be inferred from Figure 12, the power coefficient curve of the turbine in position 5 is lower than in position 1 , since in the first case it is influenced by the whole line perturbation even when no turbines are installed in front of it.

The good compromise between the length of the line and the loss in efficiency was identified mainly 
analyzing the tests carried out on two turbines (see second row in Table 1) set in different longitudinal positions. The results of these tests are reported in Figure 13 which shows the loss in efficiency of the system with the first turbine in position 1 and the second one in position 2, 3, 4 and 5 .

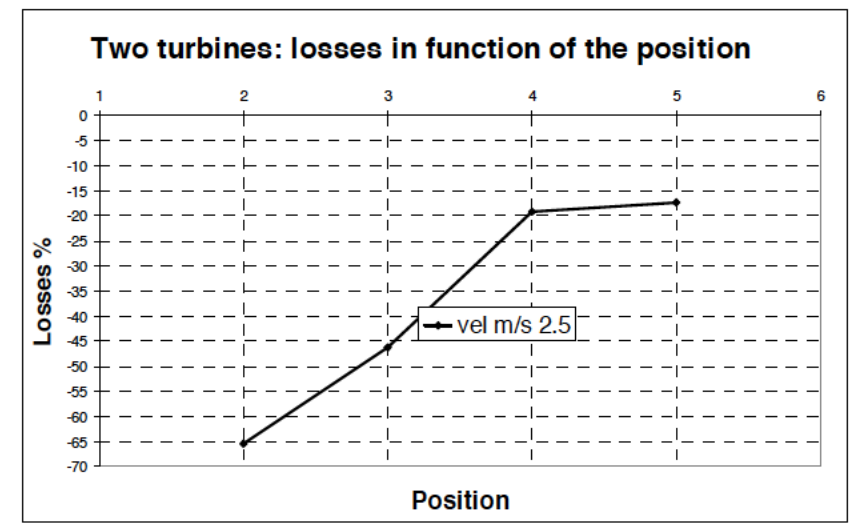

Figure 13: Two turbine comparisons.

Taking into account the information obtained from single line tests, the 4 lines configuration was designed in a modular way in order to easily change transversal poles of different lengths to identify an optimal configuration like showed in Figure 14.
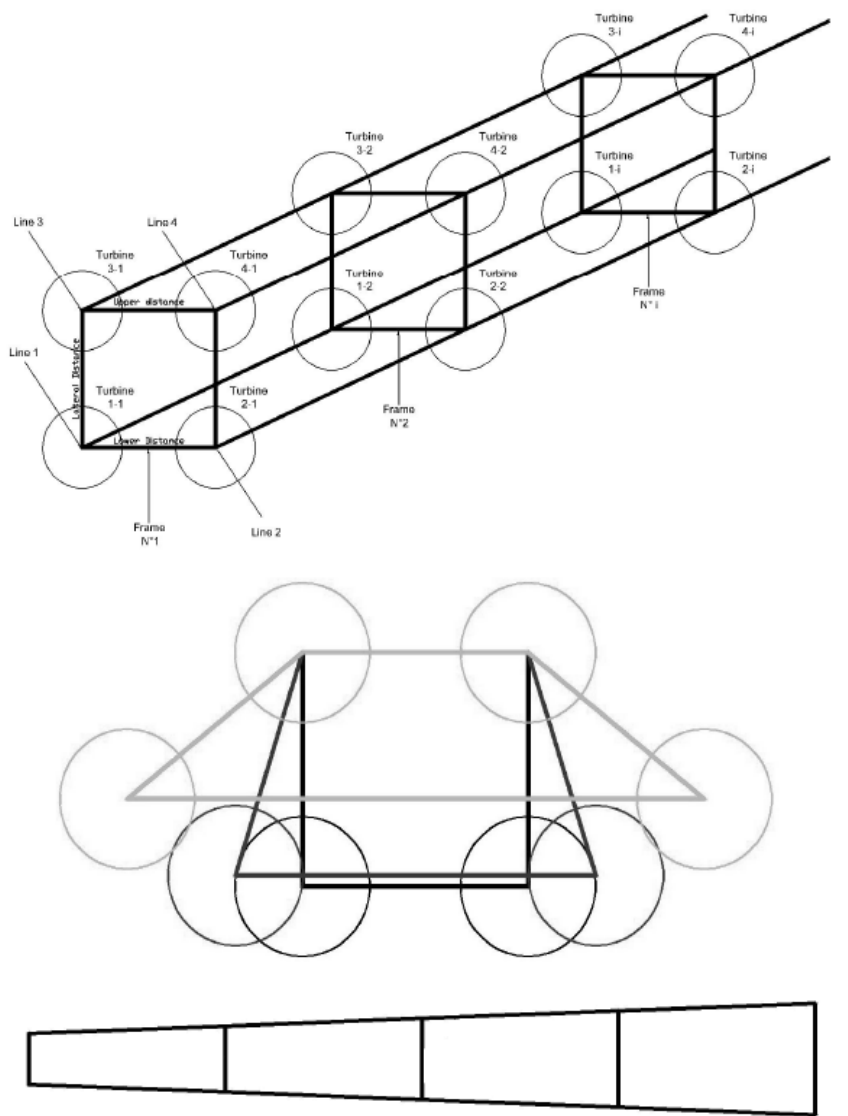

Figure 14: Four lines configuration: modular concept.
The measurements were carried out only on one of the four lines of turbines. It was verified that the other lines had an equal behaviour of the instrumented line.

Figure 15 reports the average power coefficient, obtained from the total single line measured data and dividing for the number of turbines set on the same line, for the 'closed' configuration, i.e. the squared box shape with minimum distance between turbines. As it can be seen, the efficiency is quite low.

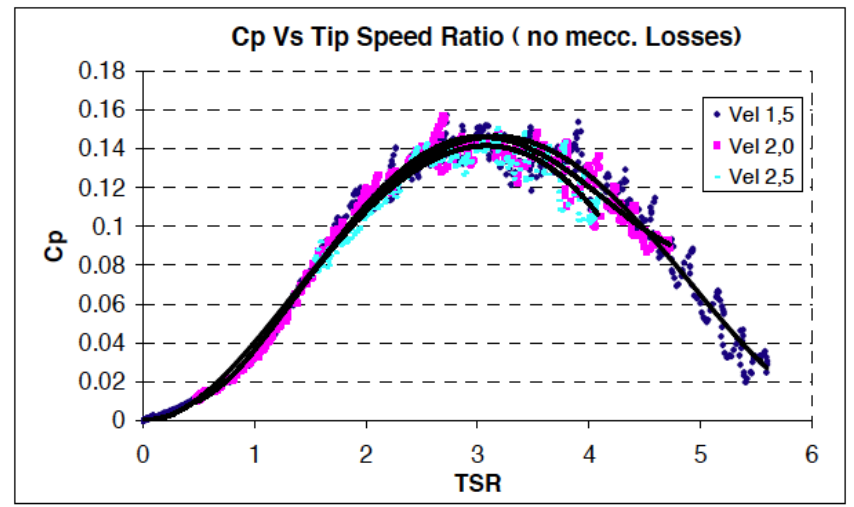

Figure 15: Average power coefficient vs TSR.

Using this configuration as reference, the best compromise between the efficiency and lateral distance was investigated.

In Figure 16 the average power coefficient of different tested lateral distances between the turbines is reported.

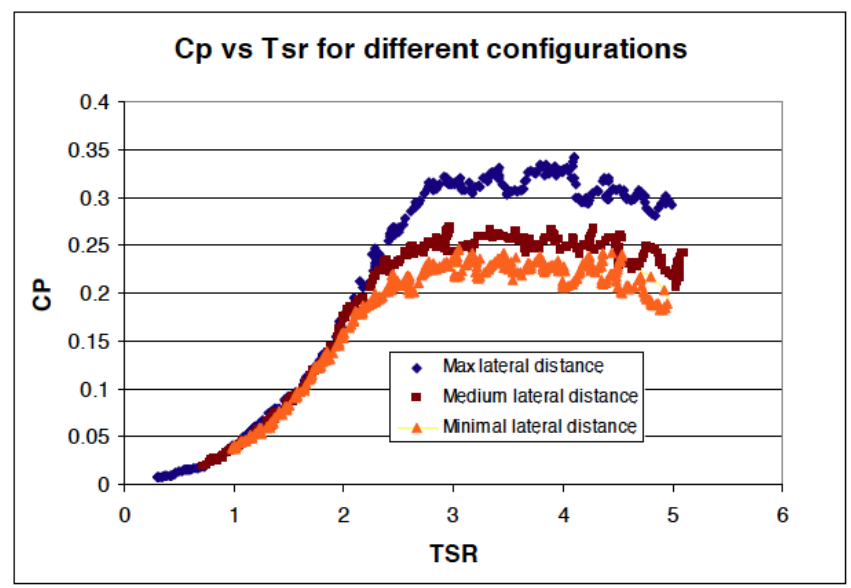

Figure 16: Comparison between different lateral distances.

\section{‘REAL FIELD’ EXPERIMENTAL TESTS}

The series of tests performed on the real site in the Messina Strait were mainly aimed to confirm the feasibility of the system and to evaluate its response in real operating conditions. 
The complete system used for the tests (Figures 17 and 18 ) in real operating conditions was formed by 3 lines, with 5 turbines set on each line, connected to a fishermen boat suitably modified to host the equipment on board.

Permanent magnet axial flux generators, designed and built in house, previously bench tested, were placed and connected to the turbine lines through transmission poles like shown in Figure 17.

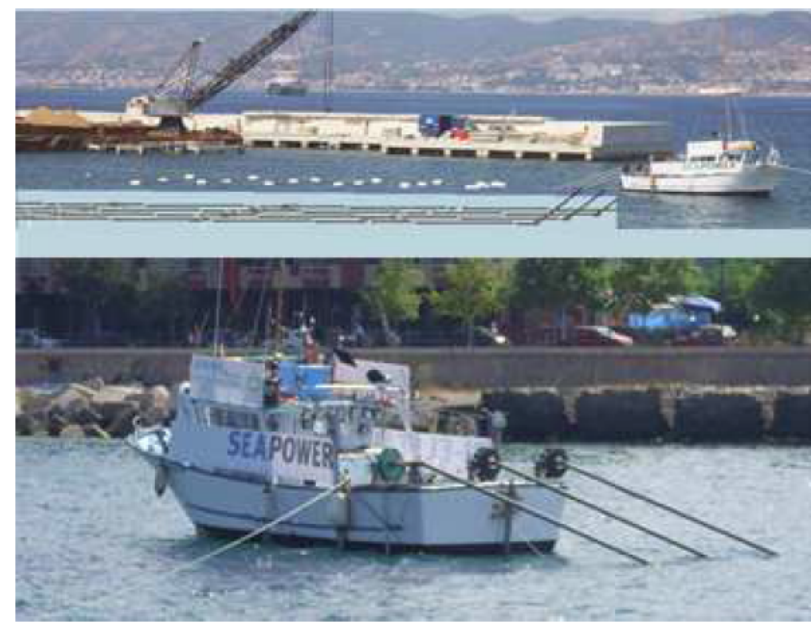

Figure 17: 'Real condition' test setup.

A comprehensive set of instruments was used to characterize system behaviour in terms of power production and applied forces.

During the tests a torque-meter was used to measure the torque applied on a line and its rotational speed, allowing the estimation of the power generated. The speed of the current was also measured by means of two current-meters placed on the side of the ship, while a load cell has been used to estimate the value of the thrust applied to a line.

The electrical load was applied trough electrical devices like lamps and water pumps.

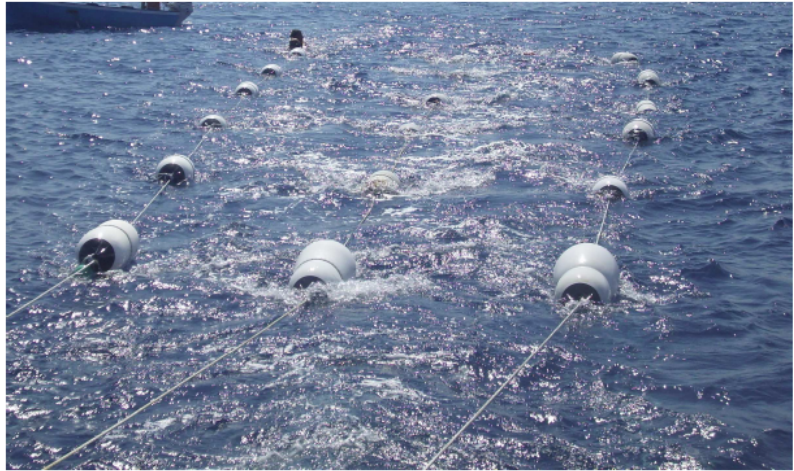

Figure 18: Lines configuration.
The maximum measured power was about $1.8 \mathrm{~kW}$ at $2 \mathrm{~m} / \mathrm{s}$ for each line.

In Figures 19, 20, 21 some examples of measurement are reported.

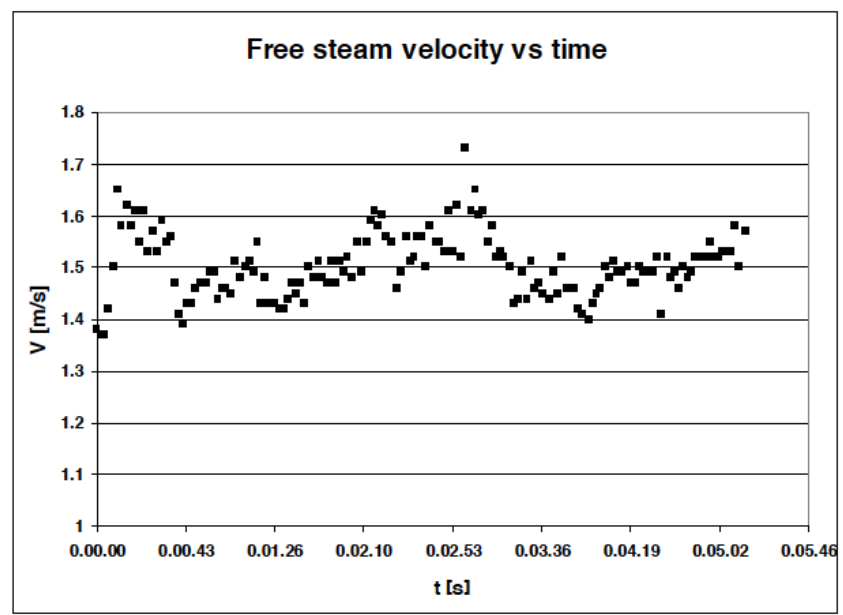

Figure 19: Current Velocity vs time.

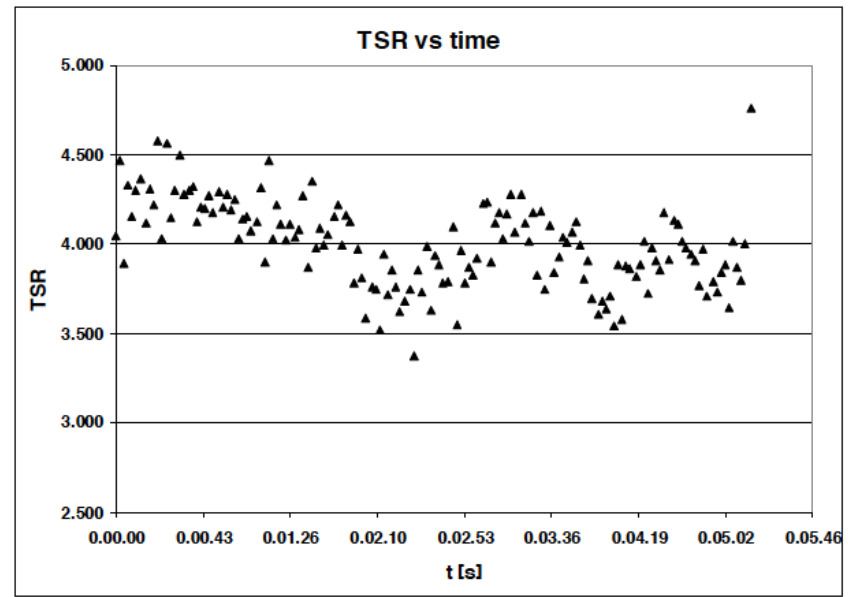

Figure 20: TSR vs time.

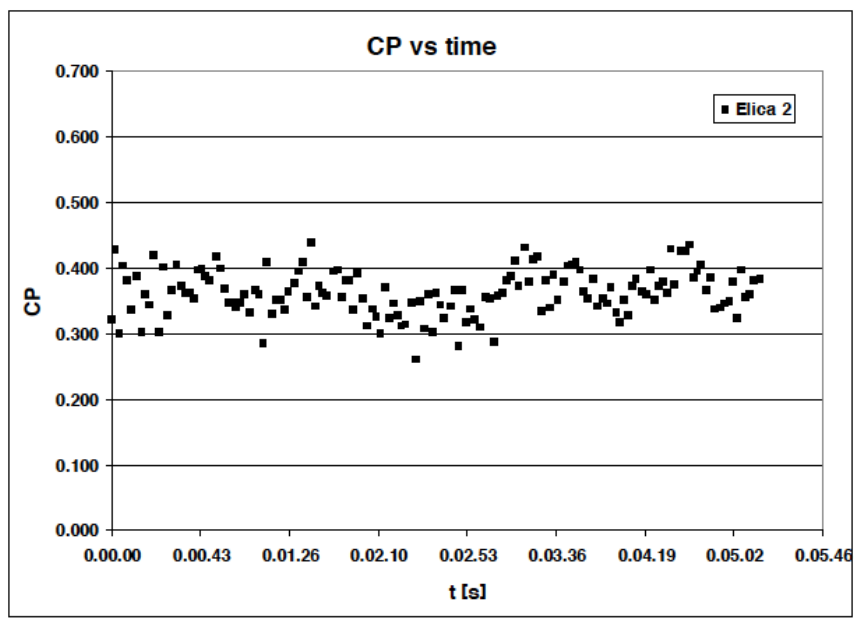

Figure 21: CP vs time. 
The maximum $\mathrm{Cp}$ reached during the tests was about 0.34 at TSR $\sim 4$. The peak value of thrust measured was $\sim 2000 \mathrm{~N}$. These values are in agreement with the towing tank tests.

\section{DYNAMIC SIMULATION}

In order to better investigate the dynamic behaviour of the system a dynamic simulation was implemented.

The numerical simulation was implemented using SIMULINK® with the blockset SIMMECHANICS.

Each pipe and corresponding buoy has been discretized as a rigid body having inertia and mass properties as shown in Figure 22. The pipes have been jointed each other using the 'gimbal' joint block simulating the cardanic joint. The buoys are linked to the pipes trough ropes which have been discretized by means of several rigid body linked each other using the 'gimbal' joint block. The hydrostatic force on the buoys is computed taking into account the vertical displacement of the buoys centre of mass.

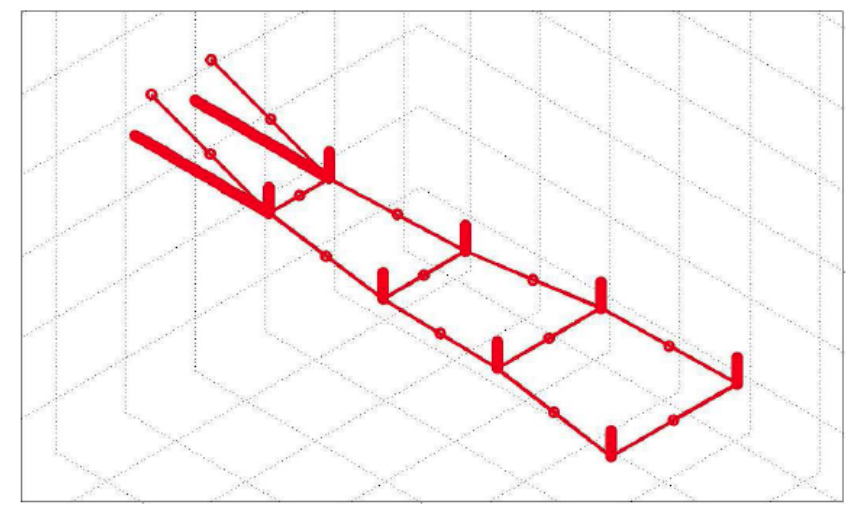

Figure 22: System discretization.

The input of the dynamic system is the wave frequency and amplitude, the output is the displacement and the internal forces of the system (Figure 23).

The fluid damping $\left(F_{\text {Damp }}\right)$ was modelled trough the Morison force [10] per unit span expression:

$$
F_{\text {Damp }}=\frac{1}{2} \rho C_{D} D(-\dot{y})|-\dot{y}|+\rho C_{m} A(-\ddot{y})
$$

The drag coefficient $\left(C_{D}\right)$, due to the oscillatory feature of the motion, is a function of the Keulegan and Carpenter number (Kc), and the Reynolds number, where $K c=\frac{2 \pi a}{D}$, and $\operatorname{Re}=\frac{D V_{\max }}{v}$ with $V_{\max }$ wave maximum vertical velocity [11].
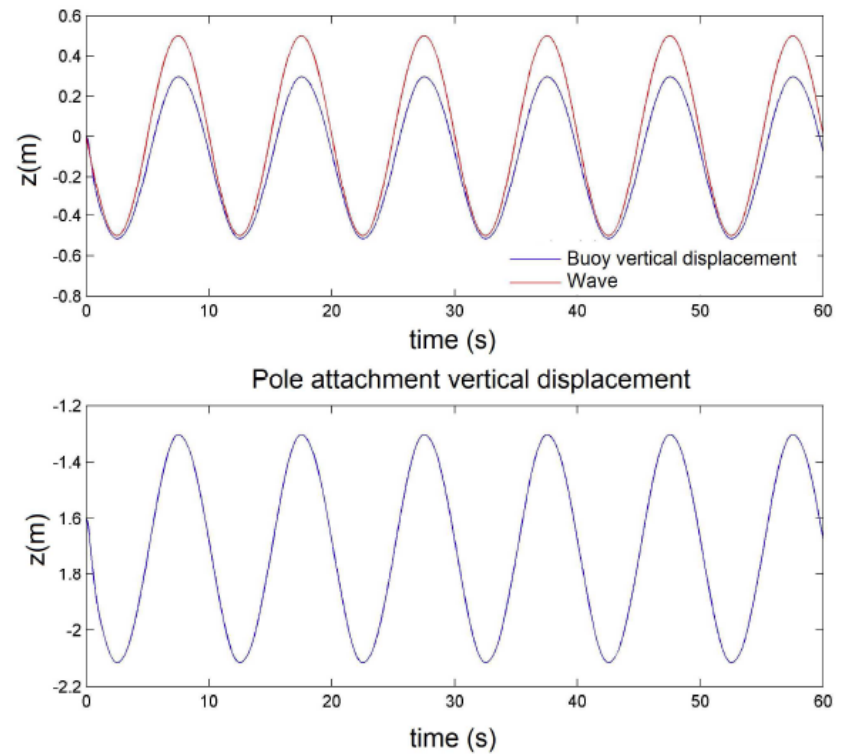

Figure 23: Dynamic simulation - Input and output example.

Only turbines thrust has been accounted for as acting force in the simulation model. The simulations have been carried out on a configuration with two lines of turbines, and with three turbines for each line.

\section{CONCLUSION}

A new prototype for exploiting tidal and river current was designed and widely tested. The experimental campaign was carried out both in the towing tank of the Department of Industrial Engineering of the University of Naples "Federico II" and in the Messina strait.

During the towing tank tests campaign the overall system configuration was optimized. The behaviour of the model was tested in 'real conditions' through a test campaign performed in the Messina Strait, showing a good agreement with the towing tank tests, and demonstrating the feasibility of the system.

Compared to other devices for the exploitation of tidal and river current energy, the main advantage of this system consists in the simplicity of underwater structure and in the absence of submarine foundations cutting down the capital cost of the whole system. However, even if tests showed the ability of the system to align itself along the current direction, handling difficulties of the whole systems were monitored especially when wind blows and the water current was not present. These situations can lead to different forces directions between floating and underwater structures which make the whole system difficult to handle. Following this experience, it is authors opinion that this type of the system should be preferably used to harness river current energy. 
A dynamic model was developed at the Department of Industrial Engineering of the University of Naples "Federico II" in order to analyze the behaviour of the system under different conditions.

\section{LIST OF SYMBOLS}

$$
\begin{array}{ll}
A & =\text { Cross section area of body } \\
a & =\text { Body motion amplitude } \\
\alpha, \text { Alpha } & =\text { Angle of attack } \\
C l & =\text { Lift coefficient } \\
C d & =\text { Drag coefficient } \\
C m & =\text { Hydrodinamic mass coefficient } \\
C P & =\text { Turbine power coefficient } \\
D & =\text { Pole diameter } \\
E=C l / C d & =\text { Aerodynamic efficiency } \\
P & =\text { Turbine Output Power } \\
R & =\text { Rotor Radius } \\
\Omega & =\text { Rotational Speed } \\
V_{\infty} & =\text { Free Stream Velocity } \\
V=\sqrt{V_{\infty}^{2}+(\Omega R)^{2}} & =\text { Local Velocity } \\
S & =\text { Rotor Frontal Area } \\
\rho & =\text { Fluid Density } \\
U & =\text { Static Pressure } \\
P s=P_{\infty}+\rho g h &
\end{array}
$$

$h$

$P v$

$P_{\infty}$

$\mathrm{Cl}_{\max }$

$\sigma_{\mathrm{v}}$

\section{REFERENCES}

[1] Coiro DP, Nicolosi F, De Marco A, Melone S, Montella F. Dynamic Behavior of a patented KOBOLD Tidal Current Turbine: Numerical and Experimental Aspects. Acta Polythecnica International Journal 2005; 45(4): 77-84.

[2] Coiro DP, Scherillo F, Troise G, Bizzarrini N, Calise G. Numerical and experimental test on an innovative device based on multiple rotors in line to tap clean energy from tidal and river current. Journal of Technology Innovations in Renewable Energy 2016.

[3] Colby JA, Corren D. Detailed Inflow Measurements for Kinetic Hydropower Systems in a Tidal Strait. Verdant Power technical report. Available from: http://www.theriteproject.com/uploads/VP DetailedInflowMea surementsKHPS.pdf

[4] http://www.verdantpower.com

[5] MacEnri J, Reed M, Thiringer T. Power quality performance of the tidal energy converter SeaGen. ASME 2011, 30th International Conference on Ocean, Offshore and Arctic Engineering, June 19-24, 2011, Rotterdam, The Netherlands.

[6] http://www.marineturbines.com/Seagen Technology

[7] http://www.cleancurrent.com/tidal-turbines

[8] http://www.lunarenergy.co.uk

[9] Grasso F. Multi-Objective Numerical Optimization Applied to Aircraft Design. Ph.D. Thesis, Department of Industrial Engineering of the University of Naples "Federico II", Napoli, Italy, December 2008.

[10] Morison JR, O'Brien MP, Johnson JW, Schaaf SA. The force exerted by surface waves on piles. Petroleum Transactions, American Institute of Mining Engineers 1950; 189: 149-154. http://dx.doi.org/10.2118/950149-g

[11] Mutlu Sumer B, Fredsoe J. Hydrodinamic around cylindrical structures. Available from: http://www.worldscientific.com 